\title{
Relationship between the fatty acid composition of rat lymphocytes and immune functions
}

\author{
Marguerite Moussa ${ }^{1}$, Jean Tkaczuk ${ }^{2}$, Jeannie Ragab ${ }^{1}$, Jésus Garcia ${ }^{1}$, Michel Abbal ${ }^{2}$, Elie Ohayon ${ }^{2}$, \\ Jacques Ghisolfi ${ }^{1}$ and Jean-Paul Thouvenot ${ }^{1}$ \\ ${ }^{1}$ Group d'Etudes en Nutrition Infantile, Laboratoire de Biochimie, CHU Purpan, 31059 Toulouse Cedex, France \\ ${ }^{2}$ Immunologie, CHU Rangueil, 31054 Toulouse Cedex, France
}

(Received 8 December 1998 - Revised 30 July 1999 - Accepted 23 August 1999)

\begin{abstract}
The effects of dietary lipids on the fatty acid composition, activation and proliferation of lymphocytes were investigated. Weanling male Wistar rats were fed for 8 weeks on one of two low-fat diets which contained $50 \mathrm{~g}$ lipid $/ \mathrm{kg}$, or one of two high-fat diets containing $200 \mathrm{~g}$ lipid/ $/ \mathrm{kg}$, from either coconut oil or soyabean oil. The fatty acid composition of phospholipids from splenocyte membranes was affected by dietary lipid manipulation, and these differences influenced lymphocyte functions. Increased levels of linoleic acid in spleen lymphocytes correlated negatively with interleukin- 2 receptor $\alpha$-chain expression determined either by measuring the mean fluorescence or by the proportion of cells staining positive for CD25, and with the cell proliferation index. However, we found a positive correlation between interleukin-2 receptor $\alpha$-chain expression determined by measuring the mean fluorescence and the cell proliferation index with the oleic acid concentration of spleen lymphocytes. Since phospholipid hydrolysis occurs early in lymphocyte activation, immunosuppressive effects induced by polyunsaturated fatty acids, described in the literature, could be due to an increase of linoleic acid or a decrease of oleic acid affecting many components of plasma-membrane-associated events involved in lymphocyte activation.
\end{abstract}

Lymphocyte proliferation: Oleic acid: Linoleic acid: Interleukin-2 receptor

The lipid composition and architecture of the cell membrane play important roles in many aspects of cellular physiology. The fatty acid composition of dietary lipids induces modifications of the cell membranes (Holman, 1968). This phenomenon also concerns lymphocyte membranes, structural modifications of which might influence lymphocyte functions.

In vitro investigations of the effects of fatty acids have shown that polyunsaturated fatty acids (PUFA) inhibit mitogen-stimulated proliferation of lymphocytes (Tsang et al. 1977; Calder et al. 1991, 1992, 1994; Calder \& Newsholme, 1992a,b; Soyland et al. 1993). Moreover, unsaturated fatty acids have also been shown to suppress the production of cytokines by mitogen-stimulated rat and human lymphocytes (Calder \& Newsholme, 1992b). Studies of the effects of fatty acids on the expression of receptors for interleukin-2 (IL-2) and transferrin by lymphocytes have shown that PUFA decrease the expression of the transferrin receptors by concanavalin A (ConA)-stimulated rat lymph-node cells (Calder \& Newsholme, 1992b).

Dietary studies in which animals have been fed on PUFAcontaining oils have yielded contradictory findings. Diets rich in linoleic acid have been shown to have no effect (Lockniskar et al. 1983), to enhance (Ossman et al. 1980) or to inhibit (Levy et al. 1983; Erickson et al. 1983; Meydani et al. 1991; Calder et al. 1995) lymphocyte proliferation. More recently, several studies (Berger et al. 1993; Yaqoob et al. 1994; Sanderson et al. 1995; Jeffery et al. 1996) have reported that feeding rats on diets containing very large amounts of olive oil significantly decreases spleen lymphocyte proliferation and natural killer-cell activity. Detailed mechanisms responsible for these functional changes remain largely undetermined.

Membrane phospholipid degradation occurs early in lymphocyte activation. Mitogens like ConA bind to cell membrane glycoproteins, including the T-cell receptorCD3 complex (Weiss et al. 1987). Mitogens acting on the T-cell receptor-CD3 complex lead to stimulation of phospholipases and to formation of second messengers which act to stimulate a cascade of reactions involving transmembrane proteins. This, in turn, leads to activation of distinct transcriptional regulators inducing IL-2 gene and IL-2 receptor $\alpha$-chain gene expression. Autocrine usage of IL-2 on its receptor induces lymphocyte proliferation. Consequently, 
modifications in dietary fatty acid intake might lead to a modification in phospholipid fatty acid composition, which could determine, after cell stimulation, alterations in this cascade of events. Thus, we decided to study how modifications in the fatty acid composition of spleen lymphocyte phospholipids, induced by dietary lipid manipulations, could influence the immune response. We studied the expression of the IL-2 receptor $\alpha$-chain which reflects lymphocyte activation, and lymphocyte proliferation. We examined the effect on these lymphocyte functions of feeding weanling rats on different dietary lipids for 8 weeks.

\section{Materials and methods}

\section{Rats and diets}

The studies were approved by the French Ministry of Agriculture, Fisheries and Nutrition. Weanling male Wistar rats (R. Janvier, Le Genest sur Isle, France), weighing 64 (SE 0.96) g, $n 28$, were housed in individual cages at $27^{\circ}$ as soon as they arrived in the laboratory, and were given free access to food and water. The rats were fed on four different diets (Institute National de Recherche Agronomique, Jouy-en-Josas, France) for 8 weeks ( $n 7$ per diet). Two low-fat (LF) diets contained $50 \mathrm{~g}$ lipid/ $\mathrm{kg}$ from either coconut oil or soyabean oil and two high-fat (HF) diets contained $200 \mathrm{~g}$ lipid/kg from either coconut oil or soyabean oil. The compositions of the diets are shown in Table 1. The fatty acid compositions of the diets are shown in Table 2.

The coconut-oil diets contained a high proportion of medium-chain saturated fatty acids, particularly lauric acid (12:0). Most of the other fatty acids in these diets were long-chain saturated fatty acids such as myristic $(14: 0)$ and palmitic acids $(16: 0)$, although oleic $(18: 1 n$ $9)$ and linoleic $(18: 2 n-6)$ acids were present. The soyabeanoil diets contained approximately $(\mathrm{g} / 100 \mathrm{~g}$ total fatty acids): 55 linoleic acid, 22 oleic acid and $8 \alpha$-linolenic acid. Linoleic acid was the main PUFA of the diets. The minimum amounts of linoleic acid were: $0.87 \%$ energy in

Table 1. Compositions $(\mathrm{g} / \mathrm{kg})$ of high-fat and low-fat experimental diets

\begin{tabular}{lcc}
\hline Ingredients & High fat & Low fat \\
\hline Maize starch & 345 & 442 \\
Cellulose & 19 & 19 \\
Sucrose & 180 & $231 \cdot 3$ \\
Casein & 211 & 211 \\
DL-Methionine & 1.3 & 1.3 \\
Lipids* & 201 & $52 \cdot 7$ \\
Mineral mix & $32 \cdot 7$ & $32 \cdot 7$ \\
Vitamin mix & 10 & 10 \\
\hline
\end{tabular}

* The diet contained either coconut oil or soyabean oil. †Provided (mg/kg diet): $\mathrm{CaHPO}_{4} \cdot 2 \mathrm{H}_{2} \mathrm{O} 380, \mathrm{~K}_{2} \mathrm{HPO}_{4}$ $240, \mathrm{CaCO}_{3} 181, \mathrm{NaCl} 70, \mathrm{MgO} 20, \mathrm{MgSO}_{4} .7 \mathrm{H}_{2} \mathrm{O}$ $90, \mathrm{FeSO}_{4} \cdot 7 \mathrm{H}_{2} \mathrm{O} 7, \mathrm{ZnSO}_{4} \cdot \mathrm{H}_{2} \mathrm{O} 5, \mathrm{MnSO}_{4} \cdot \mathrm{H}_{2} \mathrm{O} 5$, $\mathrm{CuSO}_{4} \cdot 5 \mathrm{H}_{2} \mathrm{O} 1, \mathrm{NaF} 1, \mathrm{Al}_{2}\left(\mathrm{SO}_{4}\right)_{3} \cdot \mathrm{K}_{2} \mathrm{SO}_{4} \cdot 24 \mathrm{H}_{2} \mathrm{O} 0.2$, $\mathrm{KCl} 0.08, \mathrm{CoCO}_{3} 0.08, \mathrm{Na}_{2} \mathrm{SeO}_{3} .5 \mathrm{H}_{2} \mathrm{O} 0.01$.

¥Provided (/kg diet): $\alpha$-tocopherol $4.55 \mathrm{~g}, \mathrm{~L}$-ascorbic acid $0.45 \mathrm{~g}$, choline chloride $75 \mathrm{~g}$, D-calcium pantothenate $3 \mathrm{~g}$, inositol $5 \mathrm{~g}$, menadione $2.25 \mathrm{~g}$, niacin $4.5 \mathrm{~g}$, para-aminobenzoic acid $5 \mathrm{~g}$, pyridoxine $\mathrm{HCl} 1 \mathrm{~g}$, riboflavin $1 \mathrm{~g}$, thiamin $\mathrm{HCl} 1 \mathrm{~g}$, retinyl acetate $310 \mathrm{mg}$, ergocalciferol $2.5 \mathrm{mg}$, biotin $20 \mathrm{mg}$, pteroylmonoglutamic acid $90 \mathrm{mg}$, cyanocobalamin $1.35 \mathrm{mg}$
Table 2. Fatty acid compositions ( $\mathrm{g} / 100 \mathrm{~g}$ total fatty acids) of the highfat (HF) and low-fat (LF) diets containing coconut oil (C) or soyabean oil $(S)^{*}$

(Mean of two determinations)

\begin{tabular}{lrrrr}
\hline & \multicolumn{4}{c}{ Dietary group } \\
\cline { 2 - 5 } Fatty acid & CLF & CHF & SLF & SHF \\
\hline $12: 0$ & 45.9 & $47 \cdot 2$ & - & - \\
$14: 0$ & 18.8 & 19.1 & - & - \\
$16: 0$ & 11.6 & 10.5 & $10 \cdot 8$ & $10 \cdot 8$ \\
$18: 0$ & 3.8 & 3.7 & 3.9 & 3.8 \\
$18: 1 n-9$ & 11.6 & 11.2 & 22.3 & 22.0 \\
$18: 2 n-6$ & 7.4 & 7.5 & $55 \cdot 2$ & $55 \cdot 2$ \\
$18: 3 n-3$ & $<1.0$ & $<1.0$ & 7.6 & 8.2
\end{tabular}

* The two low-fat diets contained $50 \mathrm{~g}$ lipid/kg and the two high-fat diets contained $200 \mathrm{~g} \mathrm{lipid} / \mathrm{kg}$.

the coconut LF diet, $2.86 \%$ energy in the coconut HF diet and $6.84 \%$ energy in the soyabean LF diet; the maximum amount was $21.6 \%$ energy in the soyabean HF diet.

\section{Spleen lymphocyte preparation and culture}

The rats were killed by exsanguination under light diethyl ether anaesthesia via the abdominal aorta after laparotomy and each spleen was removed and placed in $5 \mathrm{ml}$ RPMI 1640 culture medium (Eurobio, Paris, France). The spleens were dissected and homogenized in this medium. Mononuclear cells were recovered after Ficol-Hypaque (Eurobio) density gradient centrifugation $(\mathrm{d} 1.077)$ at $18000 \mathrm{~g}$ for $20 \mathrm{~min}$ at $20^{\circ}$. Cells were washed and resuspended in RPMI.

The proportion of viable cells ( $95 \%$ ) was determined by Trypan blue dye exclusion. The cells were cultured in ninety-six-well micro-titre plates at $37^{\circ}$ in an air- $\mathrm{CO}_{2}$ $(19: 1 \mathrm{v} / \mathrm{v})$ atmosphere at a density of $2 \times 10^{5}$ cells/well in RPMI supplemented with $2 \mathrm{mmol} / \mathrm{l}$ glutamine and antibiotics (penicillin, streptomycin, neomycin) and, to stimulate lymphocytes, $5 \mu \mathrm{g} / \mathrm{ml}$ ConA (Sigma, Saint Quentin Fallavier, France), the optimal concentration of ConA having been determined previously. The culture medium was also supplemented with autologous serum $(25 \mathrm{ml} / \mathrm{l})$.

\section{Measurement of spleen lymphocyte proliferation}

After $48 \mathrm{~h}$ lymphocyte culture, Mossmann's colorimetric assay with tetrazolium salts (Mossmann, 1983) was used for measurement of viable cell number. The absorbance of each sample and control (ConA-free medium) was read on a spectrophotometer at $565 \mathrm{~nm}$ in triplicate, and the proliferation index was defined as: (absorbance sample - absorbance blank)/(absorbance blank).

\section{Lipid analysis}

Lymphocytes were prepared as described earlier. Lipids were extracted with a chloroform-methanol $(2: 1, \mathrm{v} / \mathrm{v})$ mixture (Folch et al. 1957). Total phospholipids were separated by TLC on silica gel 60 plates (E. Merck, Darmstadt, Germany) using a diethyl ether-acetone mixture $(90: 30, v / v)$ as the mobile phase. GC was used to analyse total phospholipid fatty acids as previously described 
(Garcia et al. 1986). Results are expressed as $\mathrm{g} / 100 \mathrm{~g}$ total fatty acids.

\section{Phenotyping of lymphocyte populations}

Fluorescence-activated cell sorter (FACS) analysis was used to measure the presence of various markers on the surface of lymphocytes. Cytofluorimetric analysis was performed through a FACSCAN (Becton-Dickinson, San Jose, CA, USA) equipped with a single $488 \mathrm{~nm}$ Ar laser. Monoclonal antibodies were supplied by Serotec (Oxford, UK) and tricolour-streptavidin by Caltag-Tébu (Le Perray en Yvelines, France). Approximately $2 \times 10^{5}$ cells (resuspended in PBS) were incubated for $30 \mathrm{~min}$ at $4^{\circ}$ with monoclonal antibodies: anti-CD4 (W3/25 biotin), antiCD8 (MRC 0X 8 biotin) major histocompatability complex class II as B lymphocyte marker (MRC 0X 6 phycoerythrin) and ED1 fluorescein isothiocyanate as monocyte marker. The cells were then washed twice with PBS and incubated for $30 \mathrm{~min}$ at $4^{\circ}$ with tricolour-streptavidin for detection of anti-CD4 and anti-CD8 biotinylated monoclonal antibodies. After washing twice with PBS, the cells were suspended in formaldehyde in PBS $(20 \mathrm{ml} / \mathrm{l})$ and examined through a cytofluorometer. Viable cells $\left(10^{4}\right)$, were collected and gated using forward and side light scatters. The distribution of fluorescently-labelled cells was computed using LYSYS II software (Becton-Dickinson).

\section{Analysis of interleukin-2 receptor $\alpha$-chain (CD25) expression}

Flow cytometry was used to measure the expression of the IL-2 receptor $\alpha$-chain. Lymphocytes were cultured as described earlier. After $48 \mathrm{~h}$, the cells were removed and washed twice in PBS. Then the cells were incubated for $30 \mathrm{~min}$ at $4^{\circ}$ with monoclonal antibody to the $\alpha$-chain of the IL-2 receptor, anti-CD25 (MRC 0X 39 phyco-erythrin).
After washing twice with PBS, the cells were suspended in formaldehyde in PBS $(20 \mathrm{ml} / \mathrm{l})$ and examined using cytometric fluorescence-activated cell sorter analysis.

\section{Statistics}

All statistical analyses were computed with an Apple Macintosh-compatible statistical package Systat 5.1 (Systat Inc., Evanston, IL, USA). Two-way ANOVA, using fat source and fat level as the independent variables, was used to investigate significant differences of the summary variables. The Pearson correlation coefficient was used to test the relationships between the immunological variables studied and amounts of linoleic or oleic acid in lymphocyte membranes. The amounts of fatty acids in lymphocyte membranes $(\mathrm{g} / 100 \mathrm{~g}$ total fatty acids) are means for four rats per diet and those for IL-2 receptor $\alpha$-chain expression or proliferation index are means for five rats per diet.

\section{Results}

\section{Fatty acid composition of spleen lymphocytes (Table 3)}

Levels of monounsaturated fatty acids (16:1n-7 and $18: 1 n-9)$ and linoleic acid in spleen lymphocytes were significantly modifed by the fat source $(P=0.016,0.005$ and 0.001 respectively) and the fat level $(P=0.001,0.023$ and 0.001 respectively). Levels of monounsaturated fatty acids decreased with the HF diets compared with the LF diets and also decreased with the soyabean-oil diets compared with the coconut-oil diets. Docosapentaenoic acids (22:5n-6 and $22: 5 n-3)$ were only influenced by fat source; $22: 5 n-6$ was significantly lower $(P=0.017)$ in the soyabean-oil diet group than in the coconut-oil diet group while, in contrast, $22: 5 n-3$ was significantly greater in the soyabean oil group $(P=0 \cdot 012)$.

Table 3. Fatty acid compositions ( $\mathrm{g} / 100 \mathrm{~g}$ total fatty acids) of the phospholipid fractions of spleen lymphocytes from rats fed on high-fat (HF) and low-fat (LF) diets containing coconut oil (C) or soyabean oil (S)*

(Mean values with their standard errors)

\begin{tabular}{|c|c|c|c|c|c|c|c|c|c|c|}
\hline \multirow[b]{4}{*}{ Fatty acid } & \multicolumn{8}{|c|}{ Dietary group } & \multirow{2}{*}{\multicolumn{2}{|c|}{$\begin{array}{c}\text { Statistical } \\
\text { significance of } \\
\text { effect of: }(P=)\end{array}$}} \\
\hline & \multirow{2}{*}{\multicolumn{2}{|c|}{$\begin{array}{l}\text { CLF } \\
(n 3)\end{array}$}} & \multirow{2}{*}{\multicolumn{2}{|c|}{$\begin{array}{l}\mathrm{CHF} \\
(n 4)\end{array}$}} & \multirow{2}{*}{\multicolumn{2}{|c|}{$\begin{array}{l}\text { SLF } \\
(n 4)\end{array}$}} & \multirow{2}{*}{\multicolumn{2}{|c|}{$\begin{array}{l}\text { SHF } \\
(n 5)\end{array}$}} & & \\
\hline & & & & & & & & & Fat & Fat \\
\hline & Mean & SEM & Mean & SEM & Mean & SEM & Mean & SEM & source & level \\
\hline $16: 0$ & $25 \cdot 34$ & $2 \cdot 23$ & 23.04 & $2 \cdot 10$ & $25 \cdot 48$ & 1.73 & 22.04 & 3.60 & NS & NS \\
\hline $18: 0$ & 17.75 & 1.09 & 20.17 & 1.41 & 18.09 & 1.22 & $20 \cdot 10$ & 1.83 & NS & NS \\
\hline $16: 1 n-7$ & $1 \cdot 12$ & 0.14 & 0.58 & 0.05 & 0.80 & 0.13 & 0.33 & 0.01 & 0.016 & 0.001 \\
\hline $18: 1 n-9$ & $9 \cdot 61$ & 0.37 & $7 \cdot 74$ & 0.70 & $7 \cdot 31$ & 0.20 & 6.63 & 0.30 & 0.005 & 0.023 \\
\hline $18: 2 n-6$ & 5.71 & 0.55 & 9.35 & 0.39 & 10.51 & 0.92 & 13.90 & 0.96 & $<0.001$ & 0.001 \\
\hline $20: 3 n-6$ & 1.26 & 0.14 & 2.02 & 0.40 & 1.46 & 0.05 & 1.36 & 0.09 & NS & NS \\
\hline $20: 4 n-6$ & $25 \cdot 46$ & 0.60 & 24.70 & 0.94 & 23.15 & 0.55 & 23.85 & 1.74 & NS & NS \\
\hline $22: 4 n-6$ & 3.07 & 0.16 & 3.33 & 0.29 & 3.02 & 0.18 & 2.91 & 0.60 & NS & NS \\
\hline $22: 5 n-6$ & 0.92 & 0.15 & 0.61 & 0.25 & 0.35 & 0.06 & 0.22 & 0.71 & 0.017 & NS \\
\hline $22: 5 n-3$ & 0.62 & 0.12 & 0.99 & 0.04 & 1.24 & 0.21 & 1.30 & 0.17 & 0.012 & NS \\
\hline $22: 6 n-3$ & 1.47 & 0.32 & 1.29 & 0.25 & 1.92 & 0.56 & 1.48 & 0.22 & NS & NS \\
\hline $20: 3 n-9$ & 1.52 & 0.19 & 1.38 & 0.26 & 1.53 & 0.34 & 2.33 & 0.20 & NS & NS \\
\hline
\end{tabular}

\footnotetext{
${ }^{*}$ For details of diets and procedures, see Table 1 and p. 328.
} 
Table 4. Interleukin-2 receptor $\alpha$-chain (CD25) expression and cell proliferation of spleen lymphocytes from rats fed on high-fat (HF) and low-fat (LF) diets containing coconut oil (C) or soyabean oil (S)*

(Mean values with their standard errors)

\begin{tabular}{|c|c|c|c|c|c|c|c|c|c|c|}
\hline \multirow[t]{2}{*}{ Dietary group ... } & \multicolumn{2}{|c|}{$\begin{array}{l}\text { CLF } \\
(n 5)\end{array}$} & \multicolumn{2}{|c|}{$\begin{array}{l}\mathrm{CHF} \\
(n 4)\end{array}$} & \multicolumn{2}{|c|}{$\begin{array}{l}\text { SLF } \\
(n 4)\end{array}$} & \multicolumn{2}{|c|}{$\begin{array}{l}\text { SHF } \\
(n 5)\end{array}$} & \multicolumn{2}{|c|}{$\begin{array}{c}\text { Statistical significance of } \\
\text { effect of: }(P=)\end{array}$} \\
\hline & Mean & SEM & Mean & SEM & Mean & SEM & Mean & SEM & Fat source & Fat level \\
\hline \multicolumn{11}{|l|}{ CD25 expression } \\
\hline Positive cells (\%) & $57 \cdot 40$ & $4 \cdot 81$ & $55 \cdot 50$ & 3.97 & $44 \cdot 25$ & 8.46 & $37 \cdot 00$ & $8 \cdot 70$ & 0.040 & NS \\
\hline Fluorescence & 67.40 & 3.59 & $61 \cdot 70$ & 3.64 & 53.50 & 6.98 & $47 \cdot 40$ & $6 \cdot 42$ & 0.021 & NS \\
\hline Proliferation index & 1.58 & $0 \cdot 12$ & 1.03 & $0 \cdot 18$ & 0.93 & 0.14 & 0.54 & 0.13 & 0.001 & 0.005 \\
\hline
\end{tabular}

* For details of diets and procedures, see Table 1 and p. 328.

\section{Lymphocyte subpopulations}

Fluorescence-activated cell sorter analysis using monoclonal antibodies directed against CD4, CD8, a B-cell marker or a monocyte marker showed that lymphocyte preparations from spleens consisted of approximately $60 \%$ T-cells (33\% of cells were $\mathrm{CD}^{+}$and $26 \%$ were $\mathrm{CD}^{+}$), $25 \%$ B-cells and $3 \%$ monocytes. There was no significant effect of dietary lipid manipulation on lymphocyte subpopulations in the spleen.
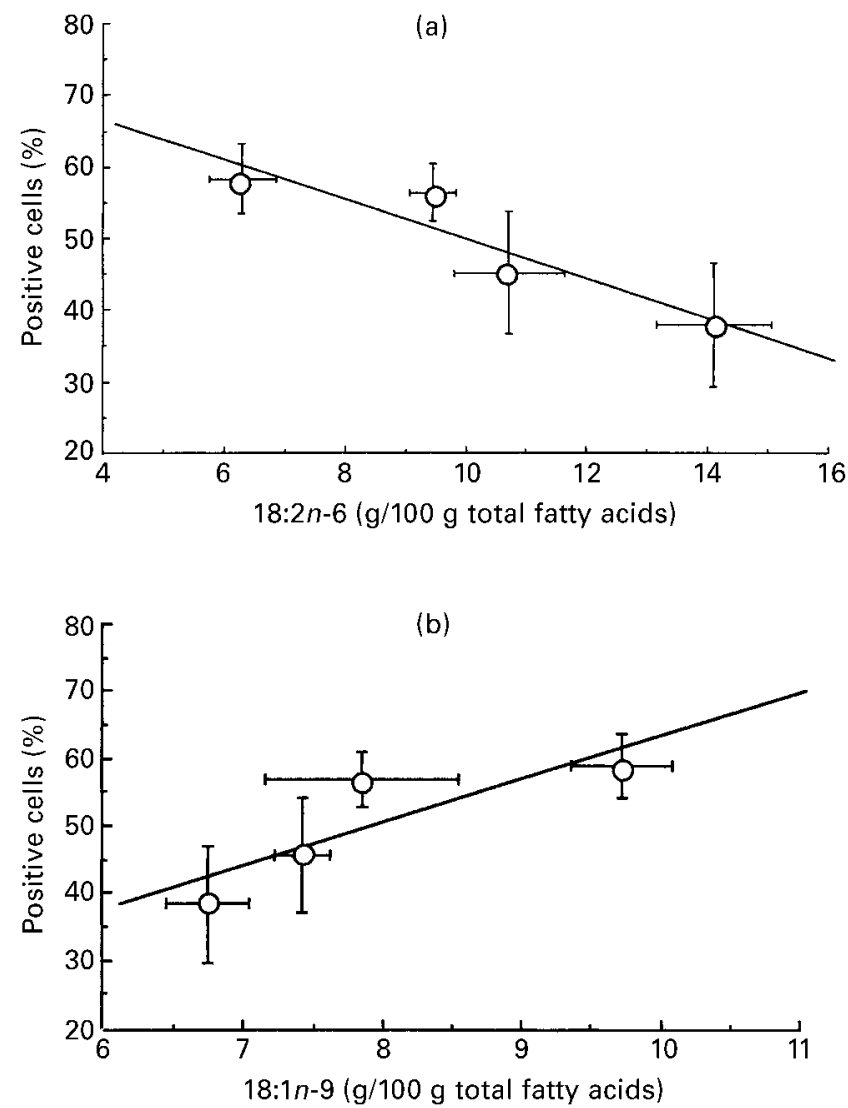

Fig. 1. Relationship between the proportion of CD25 positive spleen cells and the amount of (a) $18: 2 n-6$ or (b) $18: 1 n-9$ in spleen lymphocytes from rats fed on high-fat and low-fat diets containing coconut oil or soyabean oil. For details of diets, see Table 1. Values for spleen lymphocyte fatty acids are means for four rats with their standard errors represented by horizontal bars. Values for CD25 expression are means for five rats, with their standard errors represented by vertical bars. A significant negative correlation $(r-0.932, P=0.028)$ was found between $18: 2 n-6$ and CD25 expression (panel a).

\section{Expression of interleukin-2 receptor $\alpha$-chain (CD25)}

CD25 expression was determined either by measuring the mean fluorescence or by calculating the percentage of CD25-positive cells. The proportion of CD25-positive cells was significantly decreased by the fat source $(P=$ 0.040 ) but not by the fat level. Mean fluorescence was also significantly decreased by the fat source $(P=0.021)$ (Table 4).

A significant negative correlation was observed between IL-2 receptor $\alpha$-chain expression and the level of $18: 2 n-6$ in phopholipid membranes of spleen lymphocytes when CD25 was expressed as the percentage of positive cells (Fig. 1(a); $r-0.932, P=0.020)$ and as the mean fluorescence (Fig. 2(a); $r-0.973, P=0.001)$. A significant positive correlation was observed between IL-2 receptor $\alpha$-chain expression and the level of $18: 1 n-9$ in phospholipid membranes only when CD25 was expressed as mean fluorescence (Fig. 2(b); $r$ 0.929, $P=0.05$ ).

\section{Lymphocyte proliferation}

Cell proliferation measured as the proliferation index was significantly affected by the fat source $(P=0.001)$ and by the fat level $(P=0.005)$ (Table 4$)$. A significant negative correlation was observed between lymphocyte proliferation and the level of $18: 2 n-6$ in phopholipid membranes of spleen lymphocytes (Fig. 3(a); $r-0.990, P=0.001$ ), while a significant positive correlation was observed with $18: 1 n-9$ (Fig. 3(b); $r$ 0.984, $P=0.001$ ).

\section{Discussion}

As usually observed in other tissues, the present study confirms that dietary lipids modify the fatty acid composition of rat spleen lymphocytes. Indeed, after 8 weeks, the four diets differing in fat source and fat level resulted in significant differences in the fatty acid composition of lymphocyte phospholipids. Linoleic acid was the main PUFA of all the diets, and using the HF diets led to increasing amounts of linoleic acid in lymphocyte phospholipid membranes. The different diets used had no influence on the saturated fatty acid content of lymphocyte phospholipids but there were several significant differences in levels of the monounsaturated fatty acids $16: 1 n-7$ and $18: 1 n-9$ between lymphocytes from rats fed on the different diets. The levels of $16: 1 n-7$ and $18: 1 n-9$ were greater in 
rats fed on the coconut LF diet compared with the soyabean HF diet which contained the highest concentration of $18: 1 n-9$. Our results showed that a high level of linoleic acid in the diet induced an increase of linoleic acid with a concomitant decrease of oleic acid in the lymphocyte phospholipid membranes. The increase of monounsaturated fatty acid is usually observed with diets low in the essential fatty acids (Holman, 1968). In this case, 16:0, 18:0, $16: 1 n-7$ and $18: 1 n-9$ are synthesized endogenously. However, the high level of saturated fatty acids available in the coconut-oil diets $(80 \mathrm{~g} / 100 \mathrm{~g}$ total fatty acids) did not favour increased uptake into lymphocyte phospholipids but preferentially stimulated the synthesis of monounsaturated fatty acids by increasing $\Delta-9$ desaturase activity. The four diets used also contained increasing amounts of $\alpha$-linolenic acid. In the present study $18: 3 n-3$ represented less than $1 \mathrm{~g} / 100 \mathrm{~g}$ total fatty acids in lymphocyte phospholipids. Low levels of
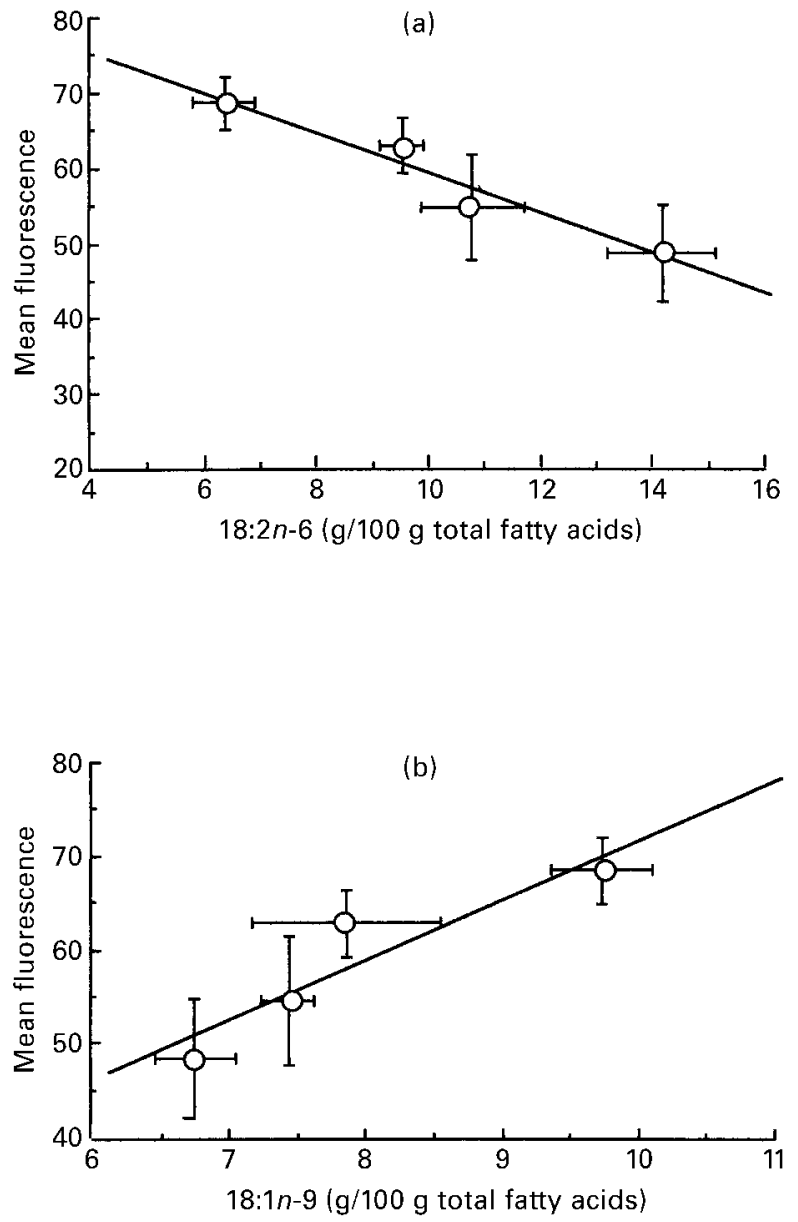

Fig. 2. Relationship between the mean fluorescence of CD25 and the amount of (a) $18: 2 n-6$ or (b) $18: 1 n-9$ in spleen lymphocytes from rats fed on high-fat and low-fat diets containing coconut oil or soyabean oil. For details of diets, see Table 1. Values for spleen lymphocyte fatty acids are means for four rats, with their standard errors represented by horizontal bars. Values for CD25 expression measured by fluorescence are means for five rats, with their standard errors represented by vertical bars. A significant negative correlation $(r$ $-0.973, P=0.001$ ) was found between $18: 2 n-6$ and CD25 expression (panel a); a significant positive correlation $(r 0.929, P=0.05)$ was found between 18:1n-9 and CD25 expression (panel b).
$18: 3 n-3$ are usually found in different tissues suggesting that $18: 3 n-3$ is rapidly metabolized (Innis, 1991). Increasing amounts of $\alpha$-linolenic acid may explain the observation that levels of $22: 5 n-3$ and $22: 6 n-3$ were higher in the rats fed on the soyabean HF diet.

Paradoxically, levels of arachidonic acid (20:4n-6) were similar in rats fed on all diets used. The level of this metabolite was preserved in spite of the low amount of its precursor, linoleic acid. We (Moussa et al. 1996) previously reported such preservation of arachidonic acid in some tissues of rats fed on an essential fatty acid-deficient diet for 4 weeks. In lymphocyte phospholipids, docosapentaenoic acid $(22: 5 n-6)$ decreased in rats fed on the soyabeanoil diets compared with the coconut-oil diets. As indicated elsewhere (Innis, 1991), synthesis of 22:5n-6 is normally limited but is increased in the liver of essential fatty aciddeficient rats. This could explain the higher level of this
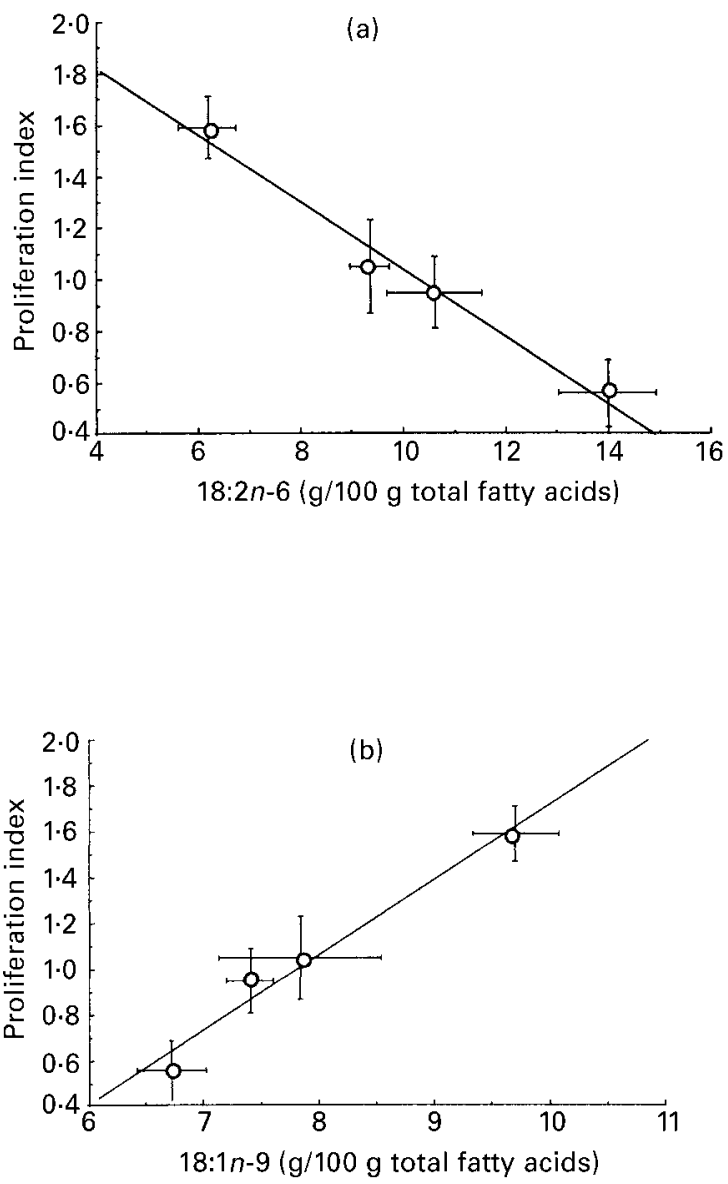

Fig. 3. Relationship between spleen lymphocyte proliferation and amount of (a) $18: 2 n-6$ or (b) $18: 1 n-9$ in spleen lymphocytes from rats fed on high-fat and low-fat diets containing coconut oil or soyabean oil. For details of diets, see Table 1. Values for spleen lymphocyte fatty acids are means for four rats, with their standard errors represented by horizontal bars. Values for proliferation index (see pp. 328 and 330) are means for five rats, with their standard errors represented by vertical bars. A significant negative correlation $(r-0.990$, $P=0.001$ ) was found between $18: 2 n-6$ and the proliferation index (panel a); a significant positive correlation $(r 0.984, P=0.001)$ was found between $18: 1 n-9$ and the proliferation index (panel b). 
fatty acid in lymphocyte phospholipids from animals fed on the coconut-oil diets.

The present study provides evidence that feeding animals on diets rich in unsaturated fatty acids results in inhibition of lymphocyte activation and lymphocyte proliferation. Dietary studies in which animals have been fed with PUFAcontaining oils before studying the lymphocyte functions, have yielded contradictory findings. Results from such studies are difficult to compare because they differ greatly in the amount of dietary fat used. Our present results confirm that both amount and type of dietary fat play a role in the modifications observed. Furthermore, some variables were modified only by the type of fat, but none was modified only by the level of fat. This observation suggests that the effects of dietary fat are particularly linked with the fatty acid composition of the diet. In our experimental protocol, designed to investigate the effects of diets rich in linoleic acid, it was necessary to use a HF diet (soyabean HF). For comparison, we used a HF diet rich in saturated fatty acids. In most of the published studies, rats were fed on diets containing $200 \mathrm{~g} / \mathrm{kg}$ of a particular lipid. The recommendations on the feeding conditions for laboratory animals suggest a diet containing $50 \mathrm{~g}$ lipid/ $\mathrm{kg}$ (Potier de Courcy et al. 1989). Thus it was important to investigate the effects of a low level of lipid $(50 \mathrm{~g} / \mathrm{kg}$ diet).

Fatty acids play a structural role in biological membranes and a change in the fatty acid composition of lymphocyte membranes might influence immune functions. A significant increase in the proportion of $n$-3 PUFA in lymphocyte phospholipids was induced by the soyabean-oil diets. These modifications concerning $n$-3 PUFA could contribute to the immunosuppressive effects observed. Indeed, several studies (Yaqoob et al. 1994; Sanderson et al. 1995) have suggested that $n-3$ PUFA may be highly immunosuppressive. However, these results were obtained with diets containing fish oils, which contain high proportions of $20: 5 n-3$ and $22: 6 n-3$. In contrast, in the present study the increase in $n-3$ PUFA in the lymphocyte phospholipids was induced by $\alpha$-linolenic acid from soyabean oil and was probably lower. Furthermore, of the PUFA, $n-3$ fatty acids are only minor components of the phospholipids of lymphocyte membranes, while linoleic acid and its derivative arachidonic acid are major components.

The proportion of arachidonic acid in lymphocyte fatty acids was not modified by the diets. From a metabolic point of view, arachidonic acid is converted to eicosanoids which are important mediators especially in immune and inflammatory responses. Our results showed that the four diets used probably did not modulate response via alterations in arachidonic acid. However, we found a significant correlation between lymphocyte function and the amount of linoleic acid present in spleen lymphocytes suggesting an immunosuppressive effect of this fatty acid. This is in agreement with other studies which have investigated the effect of diets containing $n$-6 PUFA-rich oils on immune function (Calder, 1998). Many of these show that diets very rich in linoleic acid result in suppressed lymphocyte functions. It is probably not possible to apply these findings to human diets in which the fat does not come from a single source, but in artificial nutrition, these findings would be considered of great interest. Indeed, in total parenteral nutrition the most widely used lipid emulsions are based on soyabean oil which is rich in linoleic acid. Furthermore, a high level of lipid can be administered as part of a balanced energy supply. The immunological effect of such therapy is important since it is often administered to patients who are at risk of sepsis. Indeed, such artificial nutrition has been associated with an increased susceptibility to infection (Palmblad, 1991; Guillou, 1993; Gogos \& Kalfarentzos, 1995). Our results showed that a high level of linoleic acid in the diet induced an increase in linoleic acid with a concomitant decrease in oleic acid in the phospholipid membranes. We found a significant correlation between lymphocyte function and the oleic acid present in the phospholipids of lymphocyte membranes. Our results suggest that the immunosuppressive effect of a diet rich in linoleic acid might be due to a decrease of oleic acid in the lymphocyte membrane. This highlights the beneficial role of oleic acid, a major component of olive oil which might confer health benefits, and presents a new focus of interest from a nutritional point of view. Several studies (Berger et al. 1993; Yaqoob et al. 1994; Sanderson et al. 1995; Jeffery et al. 1996) reported that feeding rats with diets containing very large amounts of olive oil significantly decreased spleen lymphocyte functions. These contradictory results could be explained by the high amount of olive oil used $(200 \mathrm{~g} / \mathrm{kg}$ diet). This would be equivalent to about $25 \%$ dietary energy from oleic acid which is in excess of the amount used in the present study. Indeed, we have shown that both the amount and the type of dietary fat could play a role in the observed modifications.

Our results suggest that the immunosuppressive effect of a high-linoleic-acid diet might be due to an increase of linoleic acid or a decrease of oleic acid in the membranes of spleen lymphocytes. As to the mechanism by which an enrichment in linoleic acid or an impoverishment in oleic acid results in a decreased response of lymphocytes to mitogenic stimulation, there are several different possibilities. A change in fatty acid composition of membrane phospholipids might be expected to affect membrane fluidity and alter the function of proteins such as CD3-T-cell receptor complex involved in the early signalling pathway leading to lymphocyte activation. However, rather than a gross modification of whole membrane fluidity, $18: 2 n-6$ enrichment or 18:1n-9 impoverishment might induce more subtle changes in specific microdomains present in the membrane. Indeed, a recent study underlined the possible functional role of these microdomains in the T-lymphocytesignalling processes (Fra et al. 1994). On the other hand, the initiation of lymphocyte proliferation involves phospholipid hydrolysis to generate second messengers and changes in the membrane fatty acid composition could influence this process. Differential effects of fatty acids on diacylglycerol mass and molecular species composition have been reported with the $n$-3 PUFA (Fowler et al. 1993).

More studies are required to establish the effect of dietary oleic acid on immune function. Given the potentially important clinical role of oleic acid, it will be important to investigate the mechanism of this immunomodulatory action by determining how specific membrane phospholipids influenced by diet affect the components of lymphocyte signal transduction and thus can affect lymphocyte functions. 


\section{Acknowledgements}

We wish to thank S. Allenbach and J. C. Cayrol for their high quality technical assistance and Professor H. Chap for scientific discussions.

\section{References}

Berger A, German JB \& Chiang BL (1993) Influence of feeding unsaturated fats on growth and immune status of mice. Journal of Nutrition 123, 225-233.

Calder PC (1998) Dietary fatty acids and immune system. Nutrition Reviews 56, 570-583.

Calder PC, Bevan SJ \& Newsholme EA (1992) The inhibition of Tlymphocyte proliferation by fatty acids is via an eicosanoid independent mechanism. Immunology 75, 108-115.

Calder PC, Bond JA, Bevan SJ, Hunt SV \& Newsholme EA (1991) Effect of fatty acids on the proliferation of concanavalin Astimulated rat lymph node lymphocyte. International Journal of Biochemistry 23, 579-588.

Calder PC, Costarosa LFBP \& Curi R (1995) Effects of feeding lipids of different fatty acid compositions upon rat lymphocyte proliferation. Life Sciences 56, 455-463.

Calder PC \& Newsholme EA (1992a) Polyunsaturated fatty acids suppress human peripheral blood lymphocyte proliferation and interleukin-2 production. Clinical Science 82, 695-700.

Calder PC \& Newsholme EA (1992b) Unsaturated fatty acids suppress interleukin-2 production and transferrin receptor expression by concanavalin A stimulated rat lymphocytes. Mediators of Inflammation 1, 107-112.

Calder PC, Yaqoob P, Harvey DJ, Watts A \& Newsholme EA (1994) Incorporation of fatty acids by concanavalin A stimulated lymphocytes and the effect on fatty acid composition and membrane fluidity. Biochemical Journal 300, 509-518.

Erickson KL, Adams DA \& McNeill CJ (1983) Dietary lipid modulation of immune responsiveness. Lipids 18, 468-474.

Folch J, Lees M \& Sloane-Stanley GH (1957) A simple method for the isolation and purification of total lipides from animal tissues. Journal of Biological Chemistry 226, 497-509.

Fowler KH, McMurray DN, Fan YY, Aukema HM \& Chapkin RS (1993) Purified dietary $n-3$ polyunsaturated fatty acids alter diacylglycerol mass and molecular species composition in concanavalin A-stimulated murine splenocytes. Biochimica et Biophysica Acta 1210, 89-96.

Fra AM, Williamson E, Simons K \& Parton RG (1994) Detergentinsoluble glycolipid microdomains in lymphocytes in the absence of caveolae. Journal of Biological Chemistry 269 , 30745-30748.

Garcia J, Ghisolfi J, Lapalu-Traon C, Periquet B, Olives JP, Boyer MJ \& Thouvenot JP (1986) Depistage d'une carence en acides gras essentiels chez l'enfant (Screening for essential fatty acid deficiency in the infant). Annales de Biologie Clinique 44, 380383.

Gogos CA \& Kalfarentzos F (1995) Total parenteral nutrition and immune system activity: a review. Nutrition 11, 339-344.

Guillou PJ (1993) The effects of lipids on some aspects of the cellular immune response. Proceedings of the Nutrition Society 52, 91-100.

Holman RT (editor) (1968) Essential Fatty Acid Deficiency. Oxford: Pergamon Press.

Innis SM (1991) Essential fatty acids in growth and development. Progress in Lipid Research 30, 39-103.

Jeffery NM, Yaqoob P, Newsholme EA \& Calder PC (1996) The effects of olive oil upon rat serum lipid levels and lymphocyte function appear to be due to oleic acid. Annals of Nutrition and Metabolism 40, 71-80.

Levy JA, Ibrahim AB, Shirai I, Okta K, Nagasawa R, Yoshida H, Estes J \& Gardner M (1982) Dietary fat affects immune response, production of antiviral factors and immune complex disease in NZB/NZW mice. Proceedings of the National Academy of Sciences USA 79, 1974-1978.

Lockniskar M, Nauss KM \& Newberne PM (1983) The effect of quality and quantity of dietary fat on the immune system. Journal of Nutrition 113, 951-961.

Meydani SN, Endres S, Woods MM, Golden BR, Soo C, MorrillLabrode A, Dinarello CA \& Gorbach SL (1991) Oral (n-3) fatty acid supplementation suppresses cytokine production and lymphocyte proliferation: comparison between young and older women. Journal of Nutrition 121, 547-555.

Mossman T (1983) Rapid colorimetric assay for cellular growth and survival: application to proliferation and cytotoxicity assays. Journal of Immunological Methods 65, 55-63.

Moussa M, Garcia J, Ghisolfi J, Periquet B \& Thouvenot JP (1996) Dietary essential fatty acid deficiency differentially affects tissues of rats. Journal of Nutrition 126, 3040-3045.

Ossman JB, Erickson KL \& Canolty NL (1980) Effects of saturation and concentration of dietary fats on lymphocyte transformation in mice. Nutrition Reports International 22, 279.

Palmblad J (1991) Intravenous lipid emulsions and host defence a critical review. Clinical Nutrition 10, 303-308.

Potier de Courcy G, Durand G, Abraham J \& Gueguen L (1989) Recommandations sur les conditions d'alimentation des animaux de laboratoire (rats et souris) (Recommendations on feeding conditions for laboratory animals (rats and mice)). Science des Aliments 9, 209-217.

Sanderson P, Yaqoob P \& Calder PC (1985) Effects of dietary lipid manipulation upon rat spleen lymphocyte functions and the expression of lymphocyte surface molecules. Journal of Nutritional and Environmental Medicine 5, 119-132.

Soyland E, Nenseter MS, Braathen L \& Drevon CA (1993) Very long chain $n-3$ and $n-6$ polyunsaturated fatty acids inhibit proliferation of human T-lymphocytes in vitro. European Journal of Clinical Investigation 23, 112-121.

Tsang WM, Weyman C \& Smith AD (1977) Effect of fatty acid mixtures on phytohaemagglutinin-stimulated lymphocytes from different species. Biochemical Society Transactions 5, 153-159.

Weiss A, Shield R, Newton M, Manger B \& Imboden J (1987) Ligand receptor inter-actions required for commitment to the activation of the interleukin 2 gene. Journal of Immunology $\mathbf{1 3 8}$, 2169-2176.

Yaqoob P, Newsholme EA \& Calder PC (1994) The effect of dietary lipid manipulation on rat lymphocyte subsets and proliferation. Immunology 82, 603-610. 